\title{
The process of adaptation "green» standards BREEAM international in Russia and role of participants
}

\author{
Valery Telichenko ${ }^{1}$, Gavin Dunn ${ }^{2}$, Andrey Benuzh ${ }^{1 *}$ \\ ${ }^{1}$ Moscow State University of Civil Engineering, Yaroslavskoe shosse, 26, Moscow, 129337, Russia \\ ${ }^{2}$ BRE Global, Bucknalls Lane, Watford, Hertfordshire, WD25 9XX, UK
}

\begin{abstract}
The article describes the first official meetings between the leaders of the Moscow State University of Civil Engineering, BRE Global Limited and the Russian Green Building Council in Moscow on the topic of the localization of the Building Research Establishment's Environmental Assessment Method (BREEAM) to for the Russian Federation. It outlines the main steps taken and the actions to be undertaken of the parties to those proposed activities. Then a brief overview is provided of the main aims of the partners' organisations, their positions in the countries and their purposes. The main part of the article summarises the benefits of an international "green" standard. There is an introduction to the National Scheme Operators, the processes involved in the BREEAM schemes and the role assessors play. The main intention for the article is to show the potential for synergy when connecting the country's largest organisations involved in sustainable construction.
\end{abstract}

\section{Introduction}

The first official meeting between the leaders of Moscow State University of Civil Engineering (MGSU), BRE Global Limited (BRE) and the Russian Green Building Council (RuGBC) was held in Moscow on the $21^{\text {st }}$ of April 2016, following the acceptance of an official invitation by MGSU's president Prof. Valery Telichenko to BREEAM director Dr. Gavin Dunn. During the meeting, the parties discussed joint scientific research, development of training programs for experts, the adaptation of BREEAM international to Russian conditions and the joint development of local standards for "green" technologies [1-4]. MGSU was represented by its Rector Andrey Volkov, the president of higher education institution, the Moscow City Council deputy Valery Telichenko, the chief of scientific and technical management Pavel Kapyrin, the head of department of scientific policy Alexey Adamtsevich, the head of department of international relations Natalia Samotesova and the head of the "National standards of green construction" laboratory Andrey Benuzh. Representing BRE Global was Chief Executive Officer Nail Trafford and the Director of BREEAM Gavin Dunn. Also, representatives of RuGBC were President Guy Eames and Director Vladimir Limin (Fig. 1).

\footnotetext{
*Corresponding author: ABenuzh@gmail.com
} 


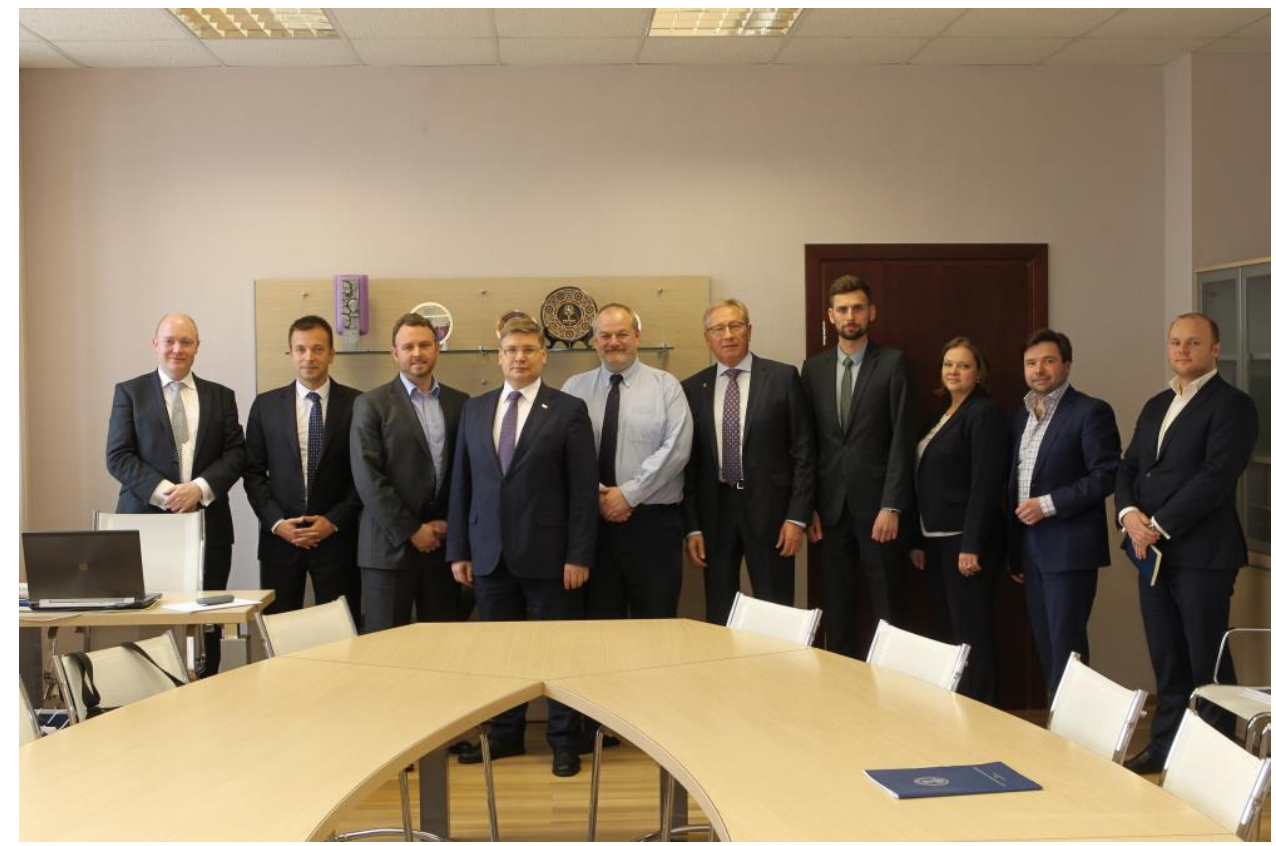

Fig. 1. The first official meeting between leaders of MGSU, BRE and RuGBC.

At the meeting MGSU Rector Andrey Volkov confirmed the interest of the University in cooperation with BRE: "Russia collects foreign experience on this question. We are national research university and our advantage is in our deep analysis, we try to adapt the best foreign experience in construction to Russian conditions. Our close cooperation will allow sharing our experience which is leading and not only in Russia". According to Valery Telichenko, the technical regulation for environmental issues in construction in Russia today are poorly developed [5, 6 and 7]. Whereas many industrialized countries are engaged very intensively in the development of "green" standards and the introduction of "green" technologies [8-11]. Certification of the building to the BREEAM standard (to standards of "green construction") allows it to minimize its impact on the environment; to guarantee that for construction there were technologies used corresponding to the basic principles of territorial sustainable development; to reduce operational costs and to increase the quality of the working and inhabited environment $[12,13]$. The director of BREEAM Gavin Dunn emphasized that when BREEAM is introduced to a country it takes into consideration local conditions and is adapted accordingly: cultural, climatic, ecological and legislative. The parties agreed on continued cooperation and transition to formalizing their agreed tasks.

At the second meeting at MGSU on $24^{\text {th }}$ of December 2016 the Memorandum of Understanding (MOU) was signed between MGSU and BRE by MGSU President Valery Telichenko and BRE Director of Sustainability Martin Townsend. The aim of the MOU is to support the long-term collaboration between two organizations to drive and foster learning and best practice at all levels of understanding, as well as scales of the built environment. The goal of the MOU at this stage was to support the cooperation between the two parties and establish a set of principles to form the foundation for a long-term relationship. This included ensuring that the common aim of both parties of supporting and transforming the built environment, in its design, construction, operation and refurbishment is achieved within Russia. Some of the points from the context of MOU are following:

- BRE and MGSU have a common and shared interest in all scales of the built environment;

- BRE and MGSU work together to promote/share resources and appropriate information 
on sustainable technologies to best inform the market;

- BRE and MGSU will work from time to time on research, which may be of mutual benefit to the members or wider international community.

MGSU President Valery Telichenko noted that the BREEAM system was applied in Russia for the Olympic buildings at Sochi, and it is now being applied to the sporting venues that are under construction for the FIFA World Cup 2018. In Russia there are currently around 60 BREEAM certified construction projects, of various types, not only sports facilities [14, 15 and 16]. "The system is not Russified at the moment, so the appraisers use it in an original English language version. The BRE made the decision to "russify" it. However, it is not enough to simply translate the text, there is a question of terminology use, its harmonization taking into account the Russian specifics. It is about the creation of a national system, and BRE is ready to assist us with this challenge. Our work is supported by government institutions in Great Britain, we also hope that we will find support from state structures in Russia too".

\section{MGSU}

The National Research Moscow State University of Civil Engineering was established in 1921. At the present moment MGSU is a leading civil engineering institute of higher education in the Russian Federation.

The University comprises 10 big institutes, of over 50 departments, and implements the training of specialists in a wide range of scientific areas. There are 40 specialized scientific laboratories; more than 50 innovative structures which are undertaking scientific and venture research in the sphere of design and construction of safe and comfortable buildings, structures and complexes, being an innovative pool of new knowledge in civil engineering. There are now more than 18000 students studying at the University.

MGSU has 6 branches in the Moscow region and one branch in the Samara region, 8 offices in the Moscow region, 3 offices in the Tumen, Smolensk and Tula regions, as well as offices in the Republic of Bashkortostan and Stavropolsk region.

The high level of MGSU graduated is confirmed by Certificates of the correspondence of the educational activity of the University to International Standard ISO 9001:2008requirements. The certificate was awarded by the Swiss company SGS, being part of the elite of the International Accreditation Forum and is recognized in 140 countries.

\section{BRE}

BRE was established in 1921, the same year as MGSU. BRE is a world leading multidisciplinary building science centre with a mission to improve the built environment through research and knowledge generation. This includes, offering certification of fire, security and sustainability products and services to an international market.

BRE mission is 'Building a better world together'. They provide a very extensive range of advisory, expert witness, certification, testing, research, training, conference and other services, covering all aspects of the built environment and associated industries:

- Researching and writing standards.

- Testing and certification in the areas of fire, electronics, security and sustainability.

- Developing world-leading sustainability assessment methods.

- Undertaking research and consultancy for clients and regulators.

- Promulgating standards and knowledge throughout the industry through publications and events.

- Developing and delivering training. 


\section{RuGBC}

The Russian Green Building Council is a not-for-profit industry organization was established at 2009 dedicated to accelerating development and adoption of market-based green building practices.

The Council achieves these aims through:

The Council achieves these aims through:

- Setting standards of best practice through the adaptation of benchmarks and internationally accepted rating tools for the Russian market (e.g. BREEAM and LEED).

- Training for all segments of the building industry value chain.

- Facilitating members to actively lead the market.

- Providing members with networking opportunities.

\section{BREEAM}

BREEAM (Building Research Establishment's Environmental Assessment Method) is the world's first sustainability rating scheme for the built environment and has contributed much to the strong focus in the UK on sustainability in building design, construction and use. BREEAM is now an international sustainability standard that is locally adapted, operated and applied through a network of international operators, assessors and industry professionals. Through its application and use BREEAM helps clients measure and reduce the environmental impacts of their buildings and in doing so create higher value, lower risk assets.

To date, BREEAM has been used to certify over 560,000 building assessments across the building life cycle and it is being applied in over 76 countries.

Aims of BREEAM: to mitigate the life cycle impacts of buildings on the environment; to enable buildings to be recognised according to their environmental benefits; to provide a credible, environmental label for buildings; to stimulate demand and create value for sustainable buildings, building products and supply chains.

Objectives of BREEAM are following:

- To provide market recognition of buildings with a low environmental impact.

- To ensure best environmental practice is incorporated in the planning, design, construction and operation of buildings and the wider built environment.

- To define a robust, cost effective performance standard surpassing that required by regulations.

- To challenge the market to provide innovative, cost effective solutions that minimise the environmental impact of buildings.

- To raise awareness among owners, occupants, designers and operators of the benefits and value of buildings with a reduced life cycle impact on the environment.

- To allow organisations to demonstrate progress towards corporate environmental objectives.

- BREEAM is developed and operated to meet the following underlying principles:

- Ensure environmental quality through an accessible, holistic and balanced measure of environmental impacts. Use quantified measures for determining environmental quality.

- Adopt a flexible approach that encourages and rewards positive outcomes, avoiding prescribed solutions. Use robust science and best practice as the basis for quantifying and calibrating a cost effective and rigorous performance standard for defining environmental quality.

- Reflect the social and economic benefits of meeting the environmental objectives covered.

- Provide a common international framework of assessment that is tailored to meet the 'local' context including regulation, climate and sector. 
- Integrate building professionals in the development and operational processes to ensure wide understanding and accessibility.

- Adopt third party certification to ensure independence, credibility and consistency of the label.

- Adopt existing industry tools, practices and other standards wherever possible to support developments in policy and technology, build on existing skills and understanding, and minimise costs.

- Align technically and operationally with relevant international standards, including the suite of standards on the 'Sustainability of Construction Works' prepared by the European Committee for Standardisation Technical Committee CEN/TC 350.

- Engage with a representative range of stakeholders to inform ongoing development in accordance with the underlying principles and the pace of change in performance standards (accounting for policy, regulation and market capability).

The aims, objectives and principles of BREEAM are embodied within a Core Technical Standard owned and managed by BRE Global Limited. This is applied through a suite of BREEAM schemes covering aspects of the built environment life cycle. These schemes are locally developed and operated by a number of different organisations, called National Scheme Operators (NSO), across a range of countries. BRE is the NSO of BREEAM in the UK. They develop and operate a number of BREEAM Schemes for the UK and internationally, each designed to assess the environmental performance of buildings at various stages in the life cycle, and these include:

- BREEAM Infrastructure for new infrastructure projects.

- BREEAM Communities for the master-planning of a larger community of buildings.

- BREEAM New Construction for new-build non-domestic buildings.

- Home Quality Mark for new-build domestic buildings (UK only).

- BREEAM In-Use for existing non-domestic buildings in-use.

- BREEAM Refurbishment for domestic (UK only) and non-domestic building fit-outs and refurbishments.

Independent BREEAM Assessors, trained, qualified and licensed by BRE can undertake a BREEAM assessment using this scheme document and associated reporting and calculation tools.

Once an assessment is complete and quality assured BRE will issue a BREEAM certificate. The BREEAM certificate provides formal verification that the Assessor has completed an assessment of a building in accordance with the requirements of the scheme and its quality standards and procedures.

A BREEAM certificate provides assurance to any interested party that a building's BREEAM rating, at the time of certification, accurately reflects its performance against the BREEAM standard.

Anyone wishing to verify the BREEAM rating of a building can do so by either checking its BREEAM certificate, which will contain the certification mark, or by searching the BREEAM buildings listings on their web site.

Timing the engagement with and use of the BREEAM New Construction scheme via the BREEAM Assessor is essential for ensuring seamless integration of the methodology in the new-build procurement process. Without this, the ability to optimise cost-effectively the building's environmental performance and achieve the desired BREEAM rating will be compromised. Appointing a BREEAM Assessor or Accredited Professional early in the project will help in achieving the target rating without undue impacts on the flexibility of design decisions, budgets and potential solutions.

On Fig.2 serves to highlight the link between the BREEAM International New Construction 2016 assessment and certification stages and the Royal Institute of British Architects (RIBA) Outline Plan of Construction Work. 


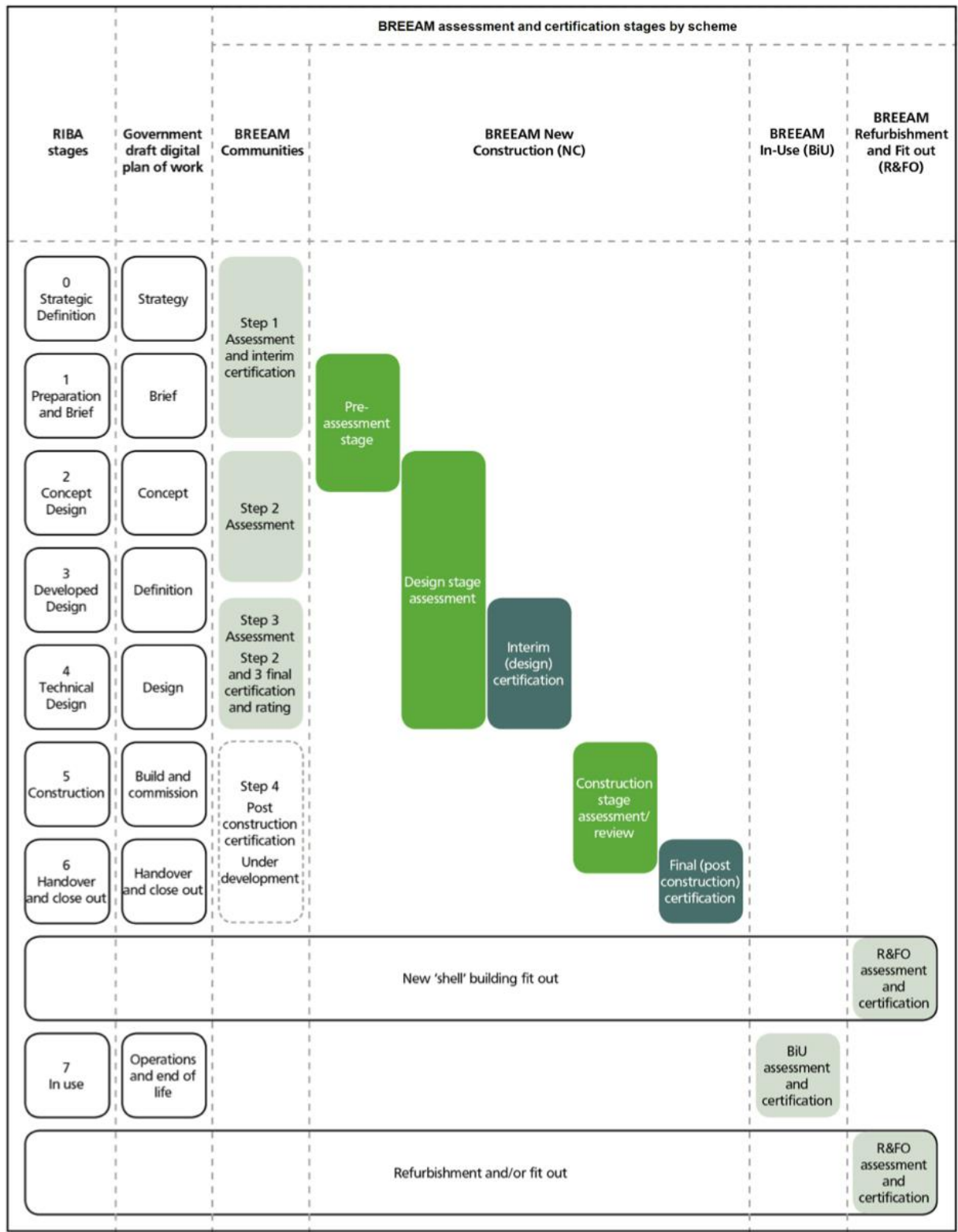

Fig. 2. BREEAM assessment stages and RIBA Outline Plan of Construction Work.

BREEAM scheme document is a technical document which has been created to:

- Enable qualified and licensed BREEAM Assessors to complete BREEAM assessments and determine a rating.

- Enable BRE to complete quality assurance reviews of a BREEAM Assessor's assessment report, in accordance with the standards to which BRE is accredited.

- Act as an aid for BREEAM Accredited Professionals (AP) to undertake project team facilitation, in terms of defining, monitoring and successfully achieving the desired BREEAM rating.

- Act as a reference for clients and members of the project team whose proposed building is being BREEAM-assessed. 
Each BREEAM scheme is split into six parts:

1. Introduction.

2. Scope of contrite scheme version.

3. BREEAM rating benchmarks, including minimum standards.

4. BREEAM evidential requirements.

5. Assessment criteria.

6. Appendices.

The Scope section describes the types of buildings and stages of assessment that this BREEAM Scheme can be applied to. Appendices provide additional scoping guidance for specific building and project types. The Scope section can be used by clients and BREEAM Assessors to check whether this is the correct BREEAM Scheme to use for their project.

The Scoring and rating section illustrates how a building's assessed performance is measured and rated. It outlines the BREEAM rating level benchmarks, the minimum BREEAM standards for each rating level and the BREEAM environmental section weightings. It also includes a description of the BREEAM assessment issues and 'credits', including BREEAM 'innovation credits', and how performance against these is calculated and expressed as a BREEAM rating.

For the purpose of formal assessment and certification, the building's actual BREEAM performance must be determined by the BREEAM Assessor using the relevant BREEAM reporting and calculation tools.

The BREEAM evidential requirements section provides guidance to assessors and project teams on the various types and forms of evidence required by the BREEAM Assessor to demonstrate compliance with BREEAM criteria. This includes a description of why BREEAM requires an auditable trail of evidence.

The Assessment criteria section includes the individual BREEAM assessment issues, categorised in 10 environmental sections. Each issue defines a level of performance (the assessment criteria) against which the assessed building demonstrates compliance (using appropriate project information, i.e. evidence) in order to achieve a corresponding number of available BREEAM credits.

The majority of BREEAM issues and credits are tradable, meaning that a client and their project team can pick and choose which to target in order to build their BREEAM performance score and achieve the desired BREEAM rating. Several BREEAM issues have minimum standards, meaning that to achieve a particular BREEAM rating specific credits or criteria must be achieved (BREEAM's minimum standards are outlined in the Scoring and rating BREEAM-assessed buildings section).

Each BREEAM issue is structured as follows:

1. Issue information: This contains the assessment issue reference, title, number of credits available and whether the issue forms part of BREEAM's minimum standards.

2. Aim: This outlines the broad objective of the issue and the impact it measures or mitigates.

3. Assessment criteria: This outlines the good and best practice performance level benchmarks and criteria. Where the building complies with the assessment criteria, as determined by the BREEAM Assessor, the relevant number of BREEAM credits can be awarded. Some issues have exemplary level criteria; where a building demonstrates that it meets exemplary level criteria, a BREEAM innovation credit can be awarded. Up to a maximum of 10 innovation credits are available.

4. Checklists and tables: This section contains any checklists and tables referenced in the assessment criteria section. This can include tables of benchmarks or building type specific performance criteria.

5. Compliance notes: These notes provide additional guidance that supports the application and interpretation of the main assessment criteria, including how to assess compliance in a 
particular location or for a particular building or project type, e.g. shell only.

6. Methodology: This section includes a description of any methodology used to determine the number of BREEAM credits achieved for a given level of building performance. It includes, for example, calculation procedures or guidance on how non-BREEAM schemes, standards or qualifications referenced in the assessment criteria relate to those criteria.

7. Evidence: This section describes the types of project information that must be provided by the design team or client and given to the BREEAM Assessor to enable verification of the building's performance against the assessment criteria and so justify the award of the relevant number of BREEAM credits. The BREEAM evidential requirements section provides further guidance on evidential requirements.

8. Additional information: This section contains any further information relevant to the application of the assessment criteria, including any definition of terms used in the assessment issue or sources of additional information that may be of use in addressing the issue.

\section{Conclusions}

The process of the adaptation activities of BREEAM in Russia is covered by the MGSU and RuGBC to support the uptake of the BREEAM International New Construction Scheme in the Russian market, and includes the provision of supporting Russian language guidance documents and materials. Based on the mission and positions of the BRE, MGSU and RuGBC, the role of participants on the adaptation can be represented in the following tasks.

For MGSU:

- Lead and provide translation of the BREEAM International new construction scheme to Russian language.

- Lead and deliver the localization process of BREEAM to national technical regulation and standards and climatic zones.

- Support the creation of BREEAM awareness level training materials.

- Embed BREEAM technical knowledge and understanding into relevant educational courses at MGSU, leading to accredited graduate recognition of students.

- Provision of local technical experts to undertake Quality Assurance reviews of BREEAM project submissions in Russian language in support of the Certification process.

- Implement strict policies ensuring independence in a process of assessments or advisory activities from BREEAM QA certification reviews.

- Implantation of BREEAM criteria to appropriate local regulations, standards and policies within wider works of MGSU for Russian authorities in government and business organization.

- Make a proposal to use BREEAM into the Moscow City procurements policies for better quality of the build environment.

- Explore possibilities to use BREEAM for refurbishment and renovating the buildings in Moscow.

- Consider further links for international joint research and collaboration. For BRE:

- Oversight and approval of the translation process for the BREEAM International scheme to the Russian language and localisation process.

- Oversight and approval of the process to develop BREEAM awareness level training. International recognition of collaboration with MGSU

- Propose the further links for international joint research and collaboration.

For RuGBC:

- Assist in translation of BREEAM International schemes to Russian language by 
organization working group of local BREEAM International assessors and APs.

- Creation the BREEAM awareness level training in Russian language.

- Host training courses of BREEAM international Assessor and AP by BRE.

- Organize training courses and conferences to promote awareness of BREEAM in Russian with reference to national technical regulations.

- Organize representation of industry stakeholders from sustainable companies on using BREEAM in Russia and future development.

- Provide market promotion on BREEAM and promotion of collaboration MGSU with BRE.

- Write reports and case studies based on a feedback from industry on the use and benefits of BREEAM in Russia.

- Help create demand for BREEAM with other GBCs in other Russian speaking countries.

\section{References}

1. A. Benuzh, V. Telichenko, Advanced Materials Research 1065-1069, 2169-2172 (2015)

2. V.I. Telichenko, V.M. Roitman, A.A. Benuzh, Integrated safety in construction, Tutorial (MISI-MGSU, Moscow, 2015)

3. V.I. Telichenko, A.A. Benuzh, Environmental glossary for a builders (MGSU, Moscow, 2016)

4. V. Telichenko, A. Benuzh, G. Eames, E. Orenburova, N. Shushunova, Procedia Engineering 153, 726-730 (2016)

5. V.I. Telichenko, A.A. Benuzh, Academia. Architecture and constructionn 1, 118-121 (2016)

6. A.N. Remizov, O.M. Ladygina, Housing construction 3, 35-38 (2014)

7. B.M. Khrustalev, V.I. Telichenko, J.S. Brakovich, V.D. Sizov, S.P. Kundas, I.M. Zolotarev, A.A. Benuzh, Engineering ecology and clean emissions of the industrial enterprises (ASV, Moscow, 2016)

8. V.I. Telichenko, A.A. Benuzh, Proceedings of the 4th International Conference on Civil Engineering and Urban Planning, CEUP 2015, 677-680 (2015)

9. R. Thakore, J. Goulding, A. Benuzh, AEI 2013: Building Solutions for Architectural Engineering - Proceedings of the 2013 Architectural Engineering National Conference, 877-890 (2013)

10. L.I. Sergienko, M.M. Podkolzin, Ecology of urbanized territories 1, 18-23 (2011)

11. A. Benuzh, E. Orenburova, MATEC Web of Conferences 86, 05014 (2016)

12. S.A. Nazarov, V.P. Grahov, Intelligent systems in production 2(22), 178-180 (2013)

13. V. Telichenko, A. Benuzh, I. Mochalov, MATEC Web of Conferences 117, 00164 (2017)

14. V.I. Telichenko, A.A. Benuzh, Industrial and Civil Engineering 10, 40-43 (2014)

15. A.A. Benuzh, M.A. Kolchigin, Vestnik MGSU 12, 161-165 (2012)

16. A.A. Benuzh, E.N. Orenburova, Housing construction 2, 14-16 (2015) 